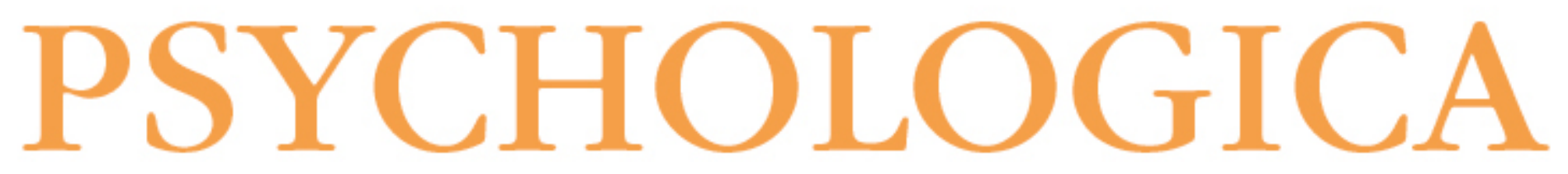

Transmissão da herança material: uma tarefa normativa das famílias envelhecidas

Autor(es): $\quad$ Patrão, Marta; Sousa, Liliana

Publicado por: Imprensa da Universidade de Coimbra

URL

persistente: URI:http://hdl.handle.net/10316.2/3455

DOI: $\quad$ DOl:http://dx.doi.org/10.14195/1647-8606_52-1_18

Accessed : $\quad$ 26-Apr-2023 15:51:14

A navegação consulta e descarregamento dos títulos inseridos nas Bibliotecas Digitais UC Digitalis, UC Pombalina e UC Impactum, pressupõem a aceitação plena e sem reservas dos Termos e Condições de Uso destas Bibliotecas Digitais, disponíveis em https://digitalis.uc.pt/pt-pt/termos.

Conforme exposto nos referidos Termos e Condições de Uso, o descarregamento de títulos de acesso restrito requer uma licença válida de autorização devendo o utilizador aceder ao(s) documento(s) a partir de um endereço de IP da instituição detentora da supramencionada licença.

Ao utilizador é apenas permitido o descarregamento para uso pessoal, pelo que o emprego do(s) título(s) descarregado(s) para outro fim, designadamente comercial, carece de autorização do respetivo autor ou editor da obra.

Na medida em que todas as obras da UC Digitalis se encontram protegidas pelo Código do Direito de Autor e Direitos Conexos e demais legislação aplicável, toda a cópia, parcial ou total, deste documento, nos casos em que é legalmente admitida, deverá conter ou fazer-se acompanhar por este aviso. 


\section{NÚMERO 52}

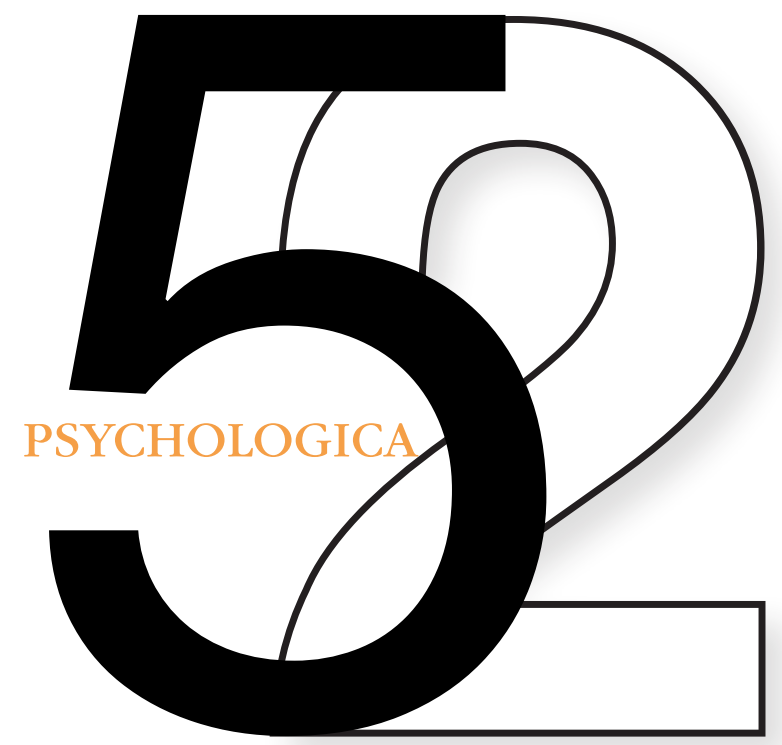

VOLUME I

IMPRENSA DA UNIVERSIDADE DE COIMBRA

FACULDADE DE PSICOLOGIA E DE CIÊNCIAS DA EDUCAÇÃO DA UNIVERSIDADE DE COIMBRA 


\title{
Transmissão da herança material: uma tarefa normativa das familias envelhecidas
}

\author{
Marta Patrão' e Liliana Sousa²
}

A transmissão da herança material é um acontecimento expectável na vida da família que se repercute na qualidade e dinâmica das suas relações no fim da vida. Porém, é um tema pouco abordado na literatura psicológica e familiar.

Este artigo apresenta um estudo exploratório sobre a transmissão da herança material, abordando-a a partir da perspectiva do ciclo da vida familiar. Partimos de entrevistas semi-estruturadas aplicadas a três focus group compostos por doadores, herdeiros e profissionais que intervêm com idosos, para compreender as suas vivências em torno da herança material. Os resultados sugerem que a transmissão da herança material emerge como uma tarefa normativa do ciclo da vida familiar associada a vicissitudes do desenvolvimento da geração idosa. A tarefa conjuga condições sócio-económicas, dinâmicas e processos familiares e confronta a família com desafios relacionais e emocionais significativos. A sua resolução contribui para o alcance da integridade individual e das relações familiares na fase final da vida.

PALAVRAS-CHAVE: Herança material; Ciclo vital da família; Família envelhecida; Tarefas do ciclo de vida.

\section{Introdução}

A herança (construção e transmissão de um legado material) constitui um tema importante na fase final da vida que todas as famílias enfrentam, independentemente da sua condição económica, social e cultural (Stum, 2000).

Nos últimos anos, diversos estudos (Sussman e tal, 1970; Stum, 2000; Kohli, 2003) têm reconhecido que a herança comporta para além do aspecto económico, aspectos emocionais e relacionais. Surge ligada a tarefas importantes desta fase da vida familiar como a gestão dos bens materiais ou a construção da integridade das relações familiares (processo de construção de significado e de desenvolvimento relacional, no qual o idoso estabelece relações na família que contribuem para o 
valorizar e dar sentido à vida) (King \& Wynne, 2004), associando-se à continuidade e viabilidade dos sistemas familiares.

Apesar das referências aos conflitos familiares derivados da transmissão das heranças serem abundantes, o conhecimento sobre os aspectos relacionais e emocionais das heranças materiais é reduzido, sobretudo na sua vertente normativa e adaptativa. Assim, neste estudo adoptamos a perspectiva do ciclo vital para abordar a herança como uma tarefa de desenvolvimento, a partir de uma perspectiva fenomenológica, recorrendo à perspectiva e vivências dos principais intervenientes no processo, pais (futuros doadores), filhos (futuros herdeiros) e profissionais que trabalham junto dos idosos ou associados ao processo de herança.

\section{Herança material e o desenvolvimento da família no fim da vida}

\subsection{Herança material: definição}

Legalmente a herança define-se como a transmissão post-mortem de bens entre gerações: conjunto dos bens, propriedades, direitos e obrigações transmitidos através de testamento ou por via da sucessão, significando que uma ou mais pessoas serão chamadas à titularidade das relações patrimoniais de outra (após a sua morte), com a atribuição dos bens que Ihe pertenciam (Telles, 1980).

Mas a experiência emocional (individual e familiar) da herança reenvia para um conceito multifacetado, em que se conjugam diversas dimensões vivenciais, conteúdos (materiais, culturais, biológicos) e processos de transmissão (jurídicos, sociais, psicológicos). Hunter \& Rowles (2005) definem três tipos da herança: i) biológica, reportando-se à passagem dos genes e das condições de saúde ou à doação do próprio corpo; ii) de valores, associada à transmissão de crenças, rituais, tradições e história familiar; e iii) material, referindo-se à transmissão de dinheiro, bens patrimoniais, bens pessoais com elevado valor simbólico ou bens materiais convertidos em valores simbólicos. Na vivência emocional da herança, os três tipos podem coexistir e a preponderância de cada um dependerá das necessidades e objectivos pessoais, da história de vida e do sentido que o indivíduo confere à sua vida.

\subsection{Herança material: gestão familiar e implicações relacionais}

A herança material (construção e transmissão de um legado material) constitui um acontecimento esperado na vida das famílias envelhecidas, sobre o qual doadores e herdeiros detêm expectativas mútuas (nem sempre coincidentes), ligadas à gestão do dinheiro e outros bens materiais. 
Com efeito, nesta fase do ciclo da vida familiar, a gestão do dinheiro constitui uma tarefa relacional (Cole, 1986), que implica: i) preparar um plano financeiro (gerir a diminuição dos rendimentos fixos e o esgotamento de reservas financeiras) e ii) redefinir a gestão dos recursos e tomar decisões relacionadas com a simplificação do quotidiano da geração mais idosa. Por exemplo, decide-se que bens manter, quais doar aos filhos (a quem e como), atribuindo-lhes também a gestão e resolução de alguns assuntos financeiros. Trata-se de uma tarefa difícil uma vez que para os idosos os recursos financeiros funcionam como uma reserva de poder e os seus bens pessoais se revestem de valor afectivo. Acresce, ainda, que as suas decisões têm implicações na gestão quotidiana dos bens e nas relações conjugais, filiais e fraternais (Sousa et al, 2004).

Nos últimos anos, o estudo das transmissões materiais na família revelou que a família funciona como uma "agência" de redistribuição económica para os seus elementos (Kohli, 2003): os bens materiais tendem a circular das gerações mais velhas para as mais novas e daquelas com maiores recursos para aquelas com menos recursos. Estas transmissões são reguladas por processos de decisão e gestão complexos que contemplam risco económico e o rendimento de pais e filhos, ao longo do ciclo de vida (McGarry, 1999) e dependem de factores como o contexto cultural, as tradições, as crenças e valores familiares e a qualidade das relações ao longo da vida (Kohli, 2004).

As transmissões materiais na família começaram por ser abordadas a partir de duas hipóteses alternativas - altruismo e troca estratégica. A hipótese altruista assume que os pais se preocupam com o bem-estar e satisfação dos filhos, e usam as transmissões materiais incondicionalmente (sem esperar retribuição) para homogeneizar os seus recursos e níveis de bem-estar económico. O valor das transmissões tende a ser desigual, privilegiando os filhos com maiores necessidades económicas (McGarry \& Schoeni, 1995).

A hipótese estratégica (Bernheim, Shleifer \& Summers, 1985) assume que os pais usam os seus bens para influenciar o comportamento dos filhos. As transferências materiais são condicionais e destinam-se a motivar a prestação de cuidados na velhice ou constituem formas de pagamento desses cuidados. Nesta hipótese, os doadores privilegiam os filhos que detêm maiores rendimentos e que vivem mais próximo dos pais (Cox \& Rank, 1992). Alguns autores sugerem que a existência de transmissões materiais ao longo da vida e/ou a expectativa de uma herança constituem bons predictores da prestação de cuidados na velhice (Caputo, 2005).

Porém, estudos posteriores acerca das redes e suporte familiar questionaram a existência de uma motivação única para a transmissão. As transmissões materiais na família estão associadas à troca de outros recursos instrumentais e afectivos (tempo, ajuda, companhia), o que remete para uma associação entre as tendên- 
cias altruísta e estratégica e não para a predominância de uma delas (Hogan, Eggebeen \& Clogg, 1993; Wollf, 200).

As motivações para a transmissão da herança material parecem ser ainda mais complexas. Os modelos anteriores não explicam porque razão as heranças (transmissão post-mortem) são frequentemente divididos em partes iguais (mesmo que isso implique perdas económicas para doadores e herdeiros) (McGarry, 1999). Estudos acerca dos padrões de distribuição dos bens entre os herdeiros indiciam que os doadores além de distribuírem as suas heranças em partes iguais (especialmente quando detêm poucas informações sobre a situação dos seus herdeiros) utilizam outras estratégias (que contrariam a igualdade) como a reciprocidade ou a resposta (altruísta) a necessidades económicas específicas de cada herdeiro (Drake \& Lawrence, 2004). Assim, a gestão da herança parece envolver um espaço motivacional mais vasto onde coexistem (e são negociadas) motivações incondicionais como o altruísmo ou a obrigação familiar, motivações condicionais como a troca estratégica ou a reciprocidade, bem como outros valores como a igualdade e a preservação da harmonia das relações familiares.

Os diferentes modos de transmissão à descendência (partição entre os irmãos em partes iguais ou desiguais, por exemplo) criam relações psicológicas e afectivas específicas, podendo constituir uma fonte de conflitos entre pais e filhos e entre irmãos.

Na família contemporânea, os conflitos ligados à herança são geralmente longos, confinados à família, suscitados pela divisão desigual dos bens ou pela violação das regras de reciprocidade e expectativas (Sussman et al, 1970; Lustbader, 1996; Stum, 2000; Kemp \& Hunt, 2001) ou ainda associados à transmissão das empresas familiares ou da terra (Titus et al, 1979), situações em que o valor patrimonial é avultado e se encontra em jogo com maior evidência a sobrevivência da família. Lustbander (1996) sugere que a distribuição dos bens pode simbolizar para os filhos, o afecto, respeito, confiança ou preferência dos pais e, assim, constituir um factor de conflito e descontentamento nas relações filiais e/ou fraternais. Com efeito, estudos sobre os padrões de transmissão e divisão dos bens entre os filhos revelam uma preferência pela divisão dos bens em partes iguais que parece responder ao desejo de preservar as relações e de evitar conflitos familiares (Bernheim \& Sverinov, 1999; Drake \& Lawrence, 2000).

\subsection{Herança material: desenvolvimento individual e familiar}

A transmissão da herança tem sido associada ao desenvolvimento psicossocial na fase final da vida (King \& Wynne, 2004; Hunter \& Rowles, 2005). A construção e 
transmissão da herança evidencia-se como uma forma de transcendência e integridade (Hunter \& Rowles, 2005), que parece radicar no papel desempenhado pelos bens materiais na continuidade do self e na preservação da identidade durante o envelhecimento. De facto, a transmissão de bens materiais nesta fase da vida é guiada por objectivos diversos como: transmitir legados pessoais e familiares, influenciar a vida dos filhos ou outros familiares significativos, assegurar que os seus bens mais estimados serão prezados pelos herdeiros (Price, Arnould \& Curasi, 2000) ou proteger a harmonia das relações familiares. Assim, os bens materiais transmitidos por herança têm valor simbólico, activam recordações e constituem símbolos de narrativas nucleares da vida familiar do indivíduo (Belk, 1990). Ao mesmo tempo, a transmissão material tem um valor relacional: simboliza afecto, reconhecimento ou rejeição entre doador e herdeiro(s) e mantém viva a memória do doador (Sussman et al., 1970; Finch et al., 1996; Kemp \& Hunt, 2000).

No desenrolar da vida familiar, a herança material tem sido caracterizada como um jogo de reciprocidades, negociação de normas de responsabilidade e obrigações familiares entre doadores e herdeiros (Sussman et al., 1970). Nesse jogo, a transmissão de pais para filhos segue um padrão intrínseco ao ciclo vital: i) os pais educam e cuidam dos filhos; ii) na idade adulta, os filhos cuidam dos pais e são recompensados pela herança; iii) o ciclo continua nas sucessivas gerações. Este processo envolve : i) a transmissão sucessiva de bens materiais entre as gerações (que é esperada e remete para funções de suporte e protecção familiar) e por outro um exercício de reciprocidade relacional (ex. recebem mais bens os filhos que cuidaram dos pais idosos) e que qualifica a relação doador-herdeiro com base na troca de serviços, bens materiais e padrões de interacção anteriores.

Deste modo, o processo subjacente à transmissão da herança material (o que transmitir, a quem, quando, e como receber ou não receber) activa temas centrais nas famílias envelhecidas como a gestão do poder, autoridade, lealdades (visiveis e invisíveis) e equilíbrio familiar entre deve e haver (dar e receber). Além disso, remete para a memória e história relacional da família, na qual estão presentes conflitos (passados ou presentes), triangulações ou alianças entre elementos da família. Ou seja, a transmissão implica uma reorganização relacional (e emocional) entre doadores e herdeiros, a qual poderá constituir um importante desafio (Sussman, 1985) nesta fase do ciclo de vida da família.

\section{Objectivos}

Este estudo exploratório pretende contribuir para conceptualizar a transmissão da herança material como uma tarefa normativa do ciclo da vida familiar no estádio 
das famílias no fim da vida. Os resultados procuram reforçar a compreensão do papel da transmissão da herança material na dinâmica familiar, nomeadamente: nas relações entre gerações (em particular entre a geração mais idosa e a geração dos filhos adultos, muitas vezes também idosa); na relação entre irmãos; e na construção da integridade familiar nos elementos idosos (doadores). Espera-se igualmente que tenham implicações na intervenção junto das famílias que enfrentam a tarefa (ou quando o tema surja associado a outros acontecimentos do ciclo de vida).

\section{Metodologia}

Para alcançar os objectivos propostos, foram realizadas entrevistas semi-estruturadas aplicadas em focus group. A amostra não aleatória e intencional baseou-se no juízo do investigador acerca de pessoas/grupos que representam as perspectivas dos intervenientes no processo familiar de herança material: i)doadores (idosos) e herdeiros, representantes de duas gerações familiares contíguas, em posições relacionais complementares (dar/receber) no processo de herança; e ii) profissionais ligados à família envelhecida e/ou à gestão da herança material, na qualidade de participantes (directos ou indirectos) no processo e que podem triangular a relação doadores-herdeiros. Para garantir a pertinência e diversidade da informação foram seleccionados sujeitos capazes de fornecer informações relevantes sobre o tema (informadores privilegiados) e que se sentissem confortáveis em discussões de grupo. Os sujeitos foram contactadas pela primeira autora e convidados pessoalmente a participar.

\section{Amostra}

O grupo de doadores compreende 8 elementos, com idades entre os 65 e os 82 anos de idade, dos quais 5 são mulheres. Cinco doadores residem em zona rural e os níveis de escolaridade são de 4 anos de escolaridade (5) e entre 5 e 9 anos de escolaridade (3). O grupo de herdeiros é composto por 5 entrevistados com idades compreendidas entre 45 e 55 anos, dos quais 3 são homens; 3 residem em zona urbana. A escolaridade indica que 3 apresentam o ensino superior e 2 têm entre 5 e 9 anos de escolaridade. O grupo de profissionais envolve 7 elementos: 2 advogados, 1 técnico de serviço social, 1 auxiliar de prestação de cuidados a idosos, 1 funcionário bancário, 1 funcionário do serviço regional de finanças, 1 técnico especialista em avaliação e inventariação de propriedades. As idades variam entre 29 e 45 anos, sendo 5 mulheres e 4 com residência urbana. 


\section{Instrumentos e procedimentos}

A entrevista em focus-group é uma técnica exploratória, que permite recolher pontos de vista dos participantes relativamente a temáticas onde o conhecimento é escasso. A entrevista foi conduzida a partir de um guião semi-estruturado, construído com base na literatura sobre o ciclo de vida familiar e heranças materiais (Sussman, 1970; Carter \& McGoldrick, 1999; Stum, 2000; Kemp \& Hunt 2001; Drake \& Lawrence, 2003; King \& Wynne, 2004). O guião foca: i) acontecimentos de vida relacionados com a emergência do tema; ii) significados e valores; iii) desafios colocados pela gestão e resolução da herança como tarefa (comportamentos e processos interpessoais subjacentes ao processo de partição e distribuição dos bens) (cf. Figura 1), este último, reconhecido na literatura como um dos mais significativos e desafiantes para a família.

Quadro 1. Objectivos e tópicos de discussão

\begin{tabular}{|c|c|}
\hline \multicolumn{2}{|c|}{ Objectivo: caracterizar a herança material como tarefa de desenvolvimento da família } \\
\hline $\begin{array}{l}\text { Caracterização } \\
\text { da tarefa }\end{array}$ & Tópicos de discussão \\
\hline $\begin{array}{l}\text { Acontecimentos } \\
\text { precipitantes }\end{array}$ & - Quando se começa a pensar e falar sobre a herança na família? \\
\hline Significados & $\begin{array}{l}\text { - O que significa dar/receber uma herança? } \\
\text { - O que leva as pessoas a dar/receber uma herança? }\end{array}$ \\
\hline Desafios & - O que costuma correr mal na herança? \\
\hline Gestão & $\begin{array}{l}\text { - O que costumam fazer as pessoas em relação à sua herança futura? } \\
\text { - A que regras recorrem para distribuir os bens? }\end{array}$ \\
\hline $\begin{array}{l}\text { Resolução e } \\
\text { integração }\end{array}$ & - O que pode tornar a herança uma experiência positiva na família? \\
\hline
\end{tabular}

A entrevista foi conduzida em interrogatório circular pela primeira autora. Todos os grupos foram introduzidos com uma breve apresentação do tema e dos objectivos do estudo, garantia da confidencialidade e solicitação de autorização. Os focus group realizaram-se num espaço cedido por uma instituição comunitária. O grupo de doadores teve duração de 120 minutos, os grupos de herdeiros e profissionais tiveram duração respectivamente de 90 e 80 minutos.

\section{Análise de dados}

As entrevistas foram gravadas em vídeo, transcritas e submetidas a análise de conteúdo, com base numa perspectiva fenomenológica e tomando como quadro conceptual a perspectiva do ciclo de vida familiar (Carter \& McGoldrick, 1999). Procura-se descrever a experiência familiar da herança, a partir das vivências dos participantes, enquanto doadores, herdeiros e profissionais. 


\section{O quadro conceptual}

Na perspectiva do ciclo da vida familiar, a família é um sistema composto por três ou quatro gerações em constante mudança ao longo do tempo. As diferentes gerações adaptam-se aos diversos estádios da vida familiar, ocorrendo um rearranjo contínuo dos papéis, pertenças, distância emocional e limites. Carter e McGoldrick (1999) consideram que a família enfrenta simultaneamente stressores verticais (mitos familiares e padrões transmitidos entre as gerações) e stressores horizontais (causados pelas transições da família à medida que esta progride no ciclo de vida). Genericamente, o ciclo da vida familiar inclui os seguintes estádios (Carter \& McGoldrick, 1999): constituição do casal ou casamento; parentalidade (famílias com filhos pequenos e famílias com filhos adolescentes); separação dos filhos adultos (ou famílias na fase intermédia da vida); família na fase final da vida (ou estádio sénior da vida). As entradas e saídas dos diversos elementos marcam a transição de umas fases para as outras. Estas transições normativas entre as fases do ciclo de vida envolvem mudanças relacionais (Carter \& McGoldrick, 1989) destinadas a apoiar a entrada, saída e desenvolvimento dos diversos elementos do sistema familiar de um modo funcional. Os períodos de transição são marcados normalmente por sentimentos de incerteza, ansiedade e sentimentos de perda, que rodeiam o processo de adaptação, reorganização e consolidação da mudança.

Em cada uma das fases do ciclo de vida, a funcionalidade do sistema familiar depende do cumprimento de tarefas que envolvem a definição dos papéis familiares e a relação com contexto externo. Carter and McGoldrick (1999) definem a tarefa central para a fase final da vida familiar como: aceitação da mudança de papéis. Outras tarefas secundárias que Ihe estão associadas incluem: adaptação ao declínio físico, a poiar o papel central da geração intermédia, lidar com a perda de pessoas significativas, revisão da vida e integração, preparação da própria morte. Nesta fase as pessoas enfrentam várias dificuldades (tais como insegurança financeira e dependência) e defrontam-se ainda com o stress associado à perda de amigos e familiares significativos. Não obstante, emergem novos papéis, tais como ser avô e a incorporação da experiência e sabedoria do idoso na vida familiar.

A transmissão da herança material constitui expectavelmente um momento onde se cruzam tensões verticais e horizontais da vida familiar.

\section{Procedimento de análise de dados}

Os dados foram analisados para os três grupos seguindo o mesmo procedimento, em que intervieram as duas autoras numa lógica de juízes independentes. O pro- 
cesso desenvolveu-se em duas fases: i) construção de categorias e subcategorias; ii) classificação das respostas nas categorias e subcategorias identificadas.

A primeira fase centrou-se na criação e teste do sistema de categorização seguindo um processo de refinamento sucessivo. As entrevistas foram lidas e revistas para fazer a selecção do material relevante, optando-se por manter o que se referia à tarefa de desenvolvimento. Com base num processo de codificação aberta, as entrevistas foram decompostas em unidades de análise, sendo critério de definição a representação de uma ideia única. Procedeu-se, então, à criação de categorias e subcategorias (Quadro 2). Na fase seguinte, dois juízes independentes categorizaram cada uma das entrevistas. Os juízes reuniram-se para analisar os seus (des)acordos e discutir todas a situações até alcançar acordo (Quadro 3).

Quadro 2. Sub/categorias: definições

\section{Acontecimentos precipitant \\ 1.1. Envelhecimento, doença e/ou dependência}

1.2. Perdas relacionais e sociais

\section{Associa-se ao desenvolvimento individual do doador, marcado pela sua "entrada na velhice": declínio físico/ cognitivo e/ou doença.}

Associa-se a marcadores do ciclo vital que indicam perdas de papéis sociais (reforma) ou de pessoas significativas (viuvez).

\begin{tabular}{ll}
\hline 2. Significados: instrumentais e relacionais \\
\hline 2.1. Conteúdos e momentos: componente mais prática e instrumental. \\
\hline Conteúdos tangiveis & $\begin{array}{l}\text { Inclui os bens materiais, com maior ou menor valor pecu- } \\
\text { niário. }\end{array}$ \\
\hline Conteúdos intangíveis & $\begin{array}{l}\text { Inclui valores e bens cuja principal valia é afectiva ou } \\
\text { simbólica. }\end{array}$ \\
\hline Transmissão em vida & $\begin{array}{l}\text { Considerado um presente ou dádiva. Apenas é herança se } \\
\text { essa for a intenção expressa dos doadores. }\end{array}$ \\
\hline Transmissão após a morte & Herança propriamente dita. \\
\hline 2.2. Significado relacional: valores que orientam. \\
\hline Altruísmo & $\begin{array}{l}\text { Cuidar das gerações mais jovens (mesmo para além da } \\
\text { morte). }\end{array}$ \\
\hline Reciprocidade & Retribuição pelos cuidados recebidos. \\
\hline Troca estratégica & Dar ou deixar para garantir cuidados na velhice. \\
\hline Corte relacional & Ruptura afectiva. \\
\hline 3. Desafios: novas funções e papéis \\
\hline $\begin{array}{l}\text { Gerir o património material } \\
\text { Inventariar e tomar conhecimento do património familiar; } \\
\text { regularizar situações legais e patrimoniais. }\end{array}$ \\
$\begin{array}{ll}\text { Gerir conflitos (em vida dos } \\
\text { doadores) }\end{array}$ & $\begin{array}{l}\text { Conflitos entre pais e filhos e entre irmãos, motivados } \\
\text { pela partição e distribuição dos bens entre os herdeiros. }\end{array}$ \\
\hline $\begin{array}{l}\text { Gerir conflitos (após a morte } \\
\text { dos doadores) }\end{array}$ & $\begin{array}{l}\text { Conflitos entre irmãos motivados pela percepção de } \\
\text { injustiças ou desfavorecimento na partição dos bens. }\end{array}$ \\
\hline $\begin{array}{l}\text { Os familiares com laços legais ou por afinidade (como } \\
\text { noras, genros, cunhados) são sentidos como possíveis } \\
\text { fontes de conflito, uma ameaça à harmonia familiar na } \\
\text { distribuição. }\end{array}$ \\
\hline
\end{tabular}




\begin{tabular}{ll}
\hline $\begin{array}{l}\text { Conciliar com outras } \\
\text { funções familiares }\end{array}$ & Cuidar dos pais idosos (doentes) e/ou assegurar o bem- \\
estar financeiro do elemento sobrevivente do casal.
\end{tabular}

\section{Gestão: responder aos desafios}

4.1. Planear

Gerir o património

Escriturar os bens, informar os filhos acerca das propriedades da família, para impedir a usurpação do património por terceiros.

Inclui: vender alguns bens e distribuir o dinheiro entre

Dividir em vida os filhos; partir os bens pelos filhos, salvaguardando a reserva de uso pelos pais.

Aconselhamento legal Prevenir problemas relacionais futuros, p.e. fazendo um testamento.

4.2. Distribuir: valores orientadores

\begin{tabular}{ll}
\hline Igualdade & Partir em partes iguais ou de valor semelhante. \\
\hline Reciprocidade & Retribuir a quem deu. \\
\hline Justiça (altruísmo) & Dar mais a quem precisa mais. \\
\hline $\begin{array}{l}\text { Respeito pelos desejos dos } \\
\text { herdeiros }\end{array}$ & $\begin{array}{l}\text { Respeitar os desejos e expectativas dos herdeiros (por } \\
\text { exemplo, dar determinado bem a quem lhe atribuir maior } \\
\text { valor afectivo). }\end{array}$ \\
\hline $\begin{array}{l}\text { Respeito pelos desejos dos } \\
\text { doadores }\end{array}$ & $\begin{array}{l}\text { Manter decisões tomadas pelos doadores, mesmo na sua } \\
\text { ausência. }\end{array}$ \\
\hline Autoridade legal (norma) & Recurso à lei para gestão da herança na família. \\
\hline 5. Resolução/integração: “estar em paz" com a gestão da tarefa \\
\hline $\begin{array}{l}\text { União } \\
\text { Manter a família unida no momento da distribuição; a } \\
\text { união familiar prévia favorece a distribuição harmoniosa } \\
\text { dos bens. }\end{array}$ \\
$\begin{array}{l}\text { A herança é um “assunto de família”, para ser gerido sem } \\
\text { a interferência de profissionais ou de familiares sem laços } \\
\text { de sangue. }\end{array}$ \\
\hline $\begin{array}{l}\text { Resolver os problemas em conjunto, conjugando os dese- } \\
\text { jos e as necessidades dos doadores e dos herdeiros. }\end{array}$ \\
\hline $\begin{array}{l}\text { Comunicação entre doadores e herdeiros sobre que bens } \\
\text { transmitir, avaliar as necessidades e desejos comuns. }\end{array}$ \\
\hline
\end{tabular}

\section{Resultados}

\subsection{Acontecimentos precipitantes}

Os acontecimentos precipitantes, na perspectiva do ciclo de vida familiar, são marcadores de transição de uma fase para a seguinte. Por norma, envolvem entradas e/ou saídas de elementos da família e desafiam (colocam a exigência da sua reorganização) os laços entre os membros da família. Herdeiros, doadores e profissionais concordam que o tema da herança emerge nas famílias envelhecidas, à medida que os pais envelhecem e se antecipa a sua perda (doença, dependência ou morte) (Quadro 3): "Quando se percebe que os pais estão a ficar velhinhos e que os podemos perder!" [herdeiro, homem, 55 anos]. 
Os profissionais e dois doadores associam a outros marcadores do ciclo vital como a reforma ou a viuvez (perda de papéis e/ou pessoas significativas): "Agora que sou viúva tenho pensado mais na herança, é um assunto que tenho de resolver!" [doador, mulher, 72 anos].

Os profissionais distinguem o caso dos casais sem filhos, para quem o tema parece emergir mais cedo, a partir dos 40 anos de idade: "Não tinham filhos e por isso quiseram saber o que aconteceria aos seus bens se um deles morresse." [advogado, mulher, 38 anos]. Além disso, os herdeiros referem que esperam que sejam os pais a abordar a questão da herança: "Nunca tinha pensado nisso. Fol o meu pai que veio ter comigo e disse que queria passar tudo para o meu nome" [herdeiro, homem, 54 anos].

\subsection{Significados}

A entrada numa nova tarefa do ciclo de vida familiar activa valores e mitos individuais e familiares; além disso envolve a reconstrução de relações que são impulsionadas por aspectos mais práticos da tarefa e obrigam a uma ponderação, reformulação e prática dos valores. As heranças (conteúdos) constroem-se ao longo da vida, contudo apenas nesta altura assumem esse estatuto.

\section{Conteúdos e momentos}

Os participantes associam a herança aos conteúdos a transmitir (bens tangíveis e intangíveis) e ao momento da transmissão (em vida dos doadores ou após a sua morte). Os conteúdos intangiveis da herança incluem: i) o nome e a memória da família (não é o valor daquilo que dão mas o que significa); ii) o investimento humano e afectivo dos doadores nos filhos (a melhor herança que o meu pai me deixou foi esforçar-se para que tirássemos um curso). Os bens tangíveis envolvem: imóveis (casas e terrenos), negócios, móveis e objectos (como loiças ou jóias).

Os doadores e os profissionais referem-se principalmente aos bens tangiveis (materiais), enquanto os herdeiros salientam mais os bens intangíveis. Os três grupos fazem emergir a distinção entre herança (transmissão após a morte) e dádivas/presentes (transmissões em vida): “Aquilo que se vai dando em vida é uma dádiva, não tem a ver com herança." [doador, homem, 73 anos].

\section{Significado relacional}

Nos três grupos sobressai o altruísmo, ou seja, os doadores deixam os seus bens materiais com o objectivo de ajudarem os filhos (herdeiros) a terem uma vida melhor. A herança é entendida como um desejo intrínseco de cuidar das gerações 
mais jovens (mesmo para além da morte), uma manifestação de generatividade: "Eu vejo os terrenos como uma forma de assegurar ofuturo dos meus filhos, quem sabe do que vão precisar no futuro!" [herdeiro, homem, 55 anos].

Mas a herança pode revestir-se ainda de outros significados relacionais como: i) reciprocidade (dou porque fui bem cuidado), apenas referida pelos doadores; ii) troca estratégica pela prestação de cuidados na velhice (dou para ser bem cuidado), sobretudo na ausência de filhos (salientada pelos profissionais); iii) corte relacional (não referida por profissionais), como nas situações em que o doador deserda como forma de proteger o património em situações de risco. Estes casos são raros e aparecem associados a rupturas afectivas. De modo contrário, a herança pode responder ao desejo de preservar o património e manter os bens na posse da família (reduto da continuidade e memória da família).

Para os herdeiros a herança material constitui um tema sensível, que desperta emoções dolorosas: "Para os pais é mais fácil falar disso... o meu pai era vivo e disse-me que queria passar tudo para o meu nome...foi como se me tivesse dado um soco no estômago... pior do que se me estivesse a dizer que me ia deserdar!" [herdeiro, homem, 54 anos]. Observa-se pois um evitamento do tema pela sua associação a emoções negativas que parecem relacionar-se com: i) com a expectativa da perda ("associo herdar à morte"); ii) com a sucessão das gerações e a assunção da passagem, directa ou indirecta, do controlo dos bens da geração mais idosa para a geração mais jovem ("senti um certo incómodo quando o meu pai me veio perguntar se queria vender um terreno ...o terreno era meu porque ele o tinha passado para meu nome mas para mim era dele").

\subsection{Desafios}

Uma tarefa do ciclo de vida familiar implica sempre o desenvolvimento de novas funções e/ou papéis quer no interior da família, quer nas relações que mantém com o exterior. São vários os stressores que obrigam a família e os seus membros a desenvolverem novas competências e a reajustarem anteriores.

Em todos os grupos, a herança é representada como um processo conflitual, complexo e com forte carga burocrática. A gestão do património familiar, em particular, a inventariação dos bens disponíveis e a sua legalização é apontada como um desafio por doadores e profissionais, embora não pelos herdeiros: " $A$ minha preocupação era tomar conta de tudo para que um dia quando eu morresse estivesse tudo legal para os meus filhos!" [doador, mulher, 67 anos].

Para os três grupos os maiores desafios incidem nos conflitos familiares entre pais e filhos e entre irmãos, principalmente em vida dos doadores (pais) e moti- 
vados pela distribuição dos bens entre os herdeiros. Os conflitos reportam-se: i) ao desacordo sobre o valor afectivo ou financeiro de um bem; ii) e à percepção de injustiças ou desfavorecimentos na partição dos bens. Os herdeiros sentem que o desafio pode surgir na gestão de conflitos familiares entre irmãos após a morte dos pais: "Depois dos pais mortos há guerras entre irmãos." [herdeiro, mulher, 49 anos].

Os três grupos são unânimes em apontar a necessidade da família se reorganizar para conciliar a gestão da herança com outras funções (como, por exemplo, o suporte aos pais idosos), assim como, a gestão da participação de elementos externos à família de sangue (como noras, genros e/ou cunhados), sentidos como possiveis fontes de conflito e/ou ameaça à harmonia na distribuição dos bens.

\subsection{Gestão da tarefa}

Perante uma nova tarefa surgem novos papéis e funções que fazem com que as famílias e os seus membros necessitem de se reorganizar em termos práticos, relacionais e emocionais. Os resultados indiciam que os participantes salientam essa reorganização em dois momentos: planear e distribuir os bens (transmitir a posse).

\section{Planear}

Profissionais e herdeiros destacam a importância de preservar o património, impedindo a sua usurpação por terceiros. O acto de escriturar os bens e informar os filhos acerca das propriedades da família e sua localização serve, na opinião dos herdeiros para proteger o património e não um interesse financeiro.

Os participantes equacionam como elemento fulcral, para uma boa gestão da herança material, a possibilidade da família proceder à divisão dos bens em vida dos pais: i) vendendo alguns bens e distribuindo o dinheiro entre os filhos, embora apenas uma parte da herança seja susceptivel de antecipação, pois alguns bens com valor relacional ou afectivo devem manter-se na posse da família; ii) ou partindo os bens pelos filhos, mas salvaguardando a reserva de uso pelos pais que mantém o poder dos pais e a hierarquia geracional. Para todos os grupos, a venda dos bens e a distribuição do seu valor monetário pelos herdeiros surge como um meio fácil de evitar conflitos, mas assume um valor pejorativo (pela redução do bem familiar a dinheiro), devendo ser encarado como um último recurso.

O aconselhamento legal emerge como uma boa forma de prevenir problemas relacionais futuros para os três grupos, com destaque para os profissionais que realçam a importância de fazer um testamento. 


\section{Distribuir}

A distribuição dos bens entre os herdeiros é um aspecto central e poderá constituir uma fonte de potenciais conflitos entre doadores e herdeiros, entre herdeiros e mesmo no casal de doadores. A Lei Portuguesa prevê a distribuição dos bens em partes iguais pelos herdeiros, independentemente do sexo e posição na fratria. Mas, as famílias detêm o seu "ethos" que pode prever outros princípios.

Os resultados evidenciam que doadores e herdeiros detêm valores diferentes sobre a distribuição dos bens. Os doadores valorizam a divisão justa (dar mais a quem precisa mais) e equitativa (partes iguais ou de valor semelhante); e, com menor relevância a reciprocidade (dar mais a quem Ihes deu mais) e o respeito pela vontade/desejo dos herdeiros. Os herdeiros referem a divisão equitativa e o respeito pelos herdeiros (a minha irmã sabia que eu queria o cordão e concordou que era para mim), mas realçam o papel activo dos pais, admitindo como principal regra o respeito pelas suas decisões, por considerarem que são "imparciais", depositando neles uma expectativa de imparcialidade e justiça: "Os pais à partida são imparciais ou deviam sê-lo!" [herdeiro, homem, 55 anos].

A este respeito, foram referidas algumas normas culturais de divisão equitativa dos bens como "ir a sortes" ou "fazer montes" (sorteio de parcelas equitativas). Mas parecem ser desvalorizadas quando comparadas com a capacidade de comunicação e entendimento entre os elementos da família: "Eu não quero montes... vamos dividindo conforme cada uma gosta e se alguém não estiver satisfeito, conversamos!" [doador, mulher, 65 anos].

Apenas os profissionais fazem referência ao recurso à lei. Ainda assim, salientam-no nas situações em que o doador queira salvaguardar a titularidade de determinado bem ou em que os conflitos familiares impeçam a resolução da herança a partir das competências da família. Os profissionais salientam ainda um planeamento baseado na igualdade (princípio básico da lei Portuguesa) e alguns admitem a importância da justiça ("ser justo") e o respeito pela vontade dos herdeiros.

\subsection{Resolução e integração da tarefa}

Quando a família resolve uma tarefa do seu ciclo vital acede a um nível de complexidade superior, desenvolvendo novos padrões relacionais e afectivos (por exemplo, novos arranjos de papéis em termos de participação e poder) para prosseguir as suas funções.

Na resolução positiva da transmissão da herança, os três grupos de participantes elegem como factores decisivos: a união entre pais e filhos ("se a herança de valores 
e a união for boa, a parte material também é mais fácil de gerir") e a adaptabilidade familiar ou capacidade para encontrar soluções conjuntas ("trocou um terreno porque sabia que ele gostava e ele compensou-a no valor").

A comunicação entre herdeiros e doadores é salientada por herdeiros e profissionais, com a função de permitir pôr em comum as expectativas e necessidades dos futuros herdeiros, para que a distribuição seja adequada: "Os pais podem conversar com os filhos sobre o que querem e o que precisam" [herdeira, mulher, 50 anos].

Na transmissão da herança, os doadores salientam o reforço dos limites da família com o exterior e enquadram a herança como um "assunto privado" ("não chamaram ninguém, nem avaliadores, nem advogados, partiram [repartir] como Ihes pareceu bem"). Associam a resolução da tarefa à consumação do processo de distribuição em família e sem a intervenção de elementos externos, nomeadamente profissionais, como prova da coesão e bons valores da família.

Quadro 3. Categorias e distribuição das respostas

\begin{tabular}{|c|c|c|c|}
\hline (Sub)categorias & $\begin{array}{l}\text { Doadores } \\
(n=8)\end{array}$ & $\begin{array}{l}\text { Herdeiros } \\
(n=5)\end{array}$ & $\begin{array}{l}\text { Profissionais } \\
\qquad(n=7)\end{array}$ \\
\hline \multicolumn{4}{|l|}{ 1. Acontecimentos precipitantes } \\
\hline Envelhecimento, doença e/ou dependência & 6 & 5 & 7 \\
\hline Perdas relacionais e sociais & 2 & & 6 \\
\hline \multicolumn{4}{|l|}{ 2. Significados } \\
\hline \multicolumn{4}{|l|}{ 2.1. Conteúdos e momentos } \\
\hline Conteúdos tangíveis & 8 & 3 & 7 \\
\hline Conteúdos intangíveis & 3 & 5 & 1 \\
\hline Transmissão em vida & & 5 & 2 \\
\hline Transmissão após a morte & 8 & 5 & 7 \\
\hline \multicolumn{4}{|l|}{ 2.2. Significado relacional de dar/receber } \\
\hline Altruísmo & 8 & 5 & 6 \\
\hline Reciprocidade & 2 & & \\
\hline Troca estratégica & 1 & 1 & 5 \\
\hline Corte relacional & 2 & 2 & \\
\hline \multicolumn{4}{|l|}{ 3. Desafios } \\
\hline Gerir o património material & 2 & & 1 \\
\hline Gerir conflitos (em vida dos doadores) & 6 & 4 & 7 \\
\hline Gerir conflitos (após a morte dos doadores) & & 5 & \\
\hline $\begin{array}{l}\text { Gerir a participação de familiares sem laços } \\
\text { sanguíneos }\end{array}$ & 3 & 2 & 3 \\
\hline Conciliar com outras funções da família & 1 & 1 & 3 \\
\hline \multicolumn{4}{|l|}{ 4. Gestão: responder aos desafios } \\
\hline \multicolumn{4}{|l|}{ 4.1. Planear } \\
\hline Gerir o património & 1 & 5 & 5 \\
\hline Distribuir em vida & 4 & 4 & 4 \\
\hline Aconselhamento legal & 3 & 3 & 7 \\
\hline
\end{tabular}




\begin{tabular}{|c|c|c|c|}
\hline 4.2. Distribuir & & & \\
\hline Igualdade & 3 & 5 & 5 \\
\hline Reciprocidade & 2 & & \\
\hline Justiça & 4 & & 2 \\
\hline Respeito pelos desejos dos herdeiros & 2 & 2 & 1 \\
\hline Respeito pelos desejos dos doadores & & 5 & \\
\hline Autoridade legal & & & 7 \\
\hline 5. Resolução/integração & & & \\
\hline União & 4 & 5 & 6 \\
\hline Reforço dos limites da família com o exterior & 3 & & \\
\hline Adaptabilidade & 3 & 4 & 5 \\
\hline Comunicação & & 2 & 3 \\
\hline
\end{tabular}

\section{Discussão}

A transmissão da herança material como tarefa do ciclo de vida familiar parece associar-se a circunstâncias do desenvolvimento da geração mais idosa (por norma os pais) que antecipam a sua perda: física (morte) e/ou emocional/cognitiva (doença e/ou dependência); ou perda de papéis sociais ou relacionais (p. ex, reforma). Note-se que a maioria das tarefas do ciclo de vida se associa a entradas ou saídas efectivas de algum membro na família, existindo nesta tarefa uma expectativa de saída (por morte), o que constitui uma especificidade. Para além disso, a tarefa sobrevém associada aos aspectos mais negativos da velhice.

Espera-se que sejam os doadores a lançar a tarefa, enquanto os herdeiros aguardam essa iniciativa sem revelarem o seu interesse, para não ferirem os sentimentos dos pais (a herança associa-se à sua morte ou doença) e/ou para não serem vistos como gananciosos e materialistas (características censuradas socialmente). Enquanto os doadores vêem a transmissão como uma necessidade, intrínseca ao seu desenvolvimento e à adaptação perante novas circunstâncias de vida, os herdeiros defendem-se da ideia de perder os pais (real ou simbolicamente). É frequente a família não querer misturar dinheiro e afectos, tentando isolar dois aspectos indissociáveis: os bens materiais detêm valor relacional e emocional e têm implicações nas relações familiares, mas jogam um papel secreto e raramente assumido.

Os protagonistas tendem a definir a herança material como o conjunto de bens materiais transmitidos aos herdeiros (filhos) após a morte dos doadores (pais), distinguindo das transmissões em vida definidas como dádivas ou presentes. À semelhança da definição legal, esta definição coloca a ênfase nos conteúdos (materiais) e no momento da transmissão (após a morte). 
Ao contrário dos herdeiros, os doadores realçam mais a componente material da herança. Isto deve-se sobretudo à intenção dos doadores (pais) de ajudar os herdeiros (filhos) a terem uma vida melhor, mas também porque os bens transmitidos parecem representar parte da sua realização material na vida e do seu sucesso enquanto pais, podendo ser encarados como um derradeiro contributo da sua função parental. Por sua vez, os herdeiros enfatizam o investimento afectivo e educativo dos pais (recusando a "materialização" da relação entre ambos) e enfatizam que os pais não são obrigados a construir uma herança avultada (deixam o que podem). A insatisfação em torno da herança que os pais deixam tende a emergir mais associada à forma como foi dividido entre irmãos (igual/ desigual) e menos à sua quantidade.

A herança representa assim ganhos e perdas que se conjugam de forma paradoxal: os ganhos derivados da herança são o resultado de uma perda. Para os doadores, a herança parece traduzir, em primeiro lugar, uma perda de controlo, real (morte) ou simbólica (dependência), sobre os seus bens materiais; e uma perda afectiva (morte e perda do contacto com os que Ihe são queridos), mas ao mesmo tempo envolve ganhos afectivos como poder ajudar os filhos, ser recordado para além da morte, ter o reconhecimento dos filhos e da comunidade e a continuidade simbólica (do próprio e da família). Para os herdeiros, a herança representa, primeiramente, a perda dos pais e simbolicamente antecipa a própria finitude (subida no degrau geracional). Todavia, comporta ganhos económicos (inerentes aos conteúdos materiais transmitidos) e afectivos, nomeadamente o afecto e o reconhecimento dos pais e da comunidade, o sentimento de pertença e a continuidade familiar. A discrepância entre perdas e ganhos parece ser contudo, mais difícil emocionalmente para os herdeiros do que para os doadores: os doadores têm ganhos essencialmente afectivos e as perdas são físicas/materiais; já os herdeiros têm ganhos materiais e as perdas são mais afectivas. Para além disso, esta tarefa acarreta para os herdeiros uma dificuldade secundária, na medida em que a reciprocidade apenas ocorre de forma indirecta, ou seja, só poderão retribuir a herança aos doadores quando se transformarem nos doadores da geração seguinte.

A herança emerge, assim, como um tópico emocional muito sensível. Os doadores têm de tomar decisões quer para manterem a família unida e bem (financeira e emocionalmente) após a sua morte (cuidar para além da morte), quer para preservarem o património material que construíram ao longo da vida. Os herdeiros deparam-se com a morte dos pais e antecipam a sua ascendência à geração mais idosa. Acrescente-se que esta experiência emocional pode ser acentuada pela negatividade que o apego pelos bens materiais (materialismo) assume socialmente.

A gestão da herança material é um processo complexo e potencialmente gerador de conflitos motivados pela partição dos bens, principalmente entre pais e filhos 
e entre irmãos. Apesar da literatura referira a ocorrência de conflitos no casal de doadores, tal não emergiu neste estudo. Por outro lado, a participação de elementos externos à família (laços legais e não de sangue) foi considerada por herdeiros e doadores como potencial fonte de conflito e ameaça à harmonia na distribuição da herança. Esta deslocação ou triangulação do conflito com os elementos por afinidade poderá estar a funcionar como um mecanismo protector da união familiar, sobretudo da preservação dos laços entre pais e filhos e entre irmãos. Nesta fase pais e filhos reaproximam-se e a salvaguarda das relações é relevante pois ambos começam a preocupar-se com a integridade das relações familiares.

Para os doadores, o planeamento da herança é importante para manter os bens na família e preparar a passagem de testemunho aos filhos. Refere-se, sobretudo, a processos formais/legais de preparação da transmissão da herança, que visam manter o património na família, evitar a usurpação dos bens e facilitar o processo de distribuição para evitar conflitos entre irmãos (por exemplo, através da venda de bens). Para os herdeiros, o planeamento significa tomar contacto com os assuntos financeiros da família e assumir a passagem de testemunho ou pelo menos aceitar essa possibilidade.

É na distribuição da herança que podem emergir mais conflitos. Herdeiros e doadores valorizam a distribuição justa e equitativa. Os herdeiros afirmam a necessidade de seguir as decisões dos pais pela sua imparcialidade, embora não fique claro neste estudo o significado dessa imparcialidade e se é coincidente para pais e filhos. Contudo, a noção de imparcialidade faz sobressair um mito familiar actual, i.e., de que os pais devem tratar os filhos de forma igual (Drake \& Lawrence, 2000). Subtrai-se, assim, o direito dos pais poderem agir de forma parcial. A ênfase na igualdade e imparcialidade parece remeter para o valor afectivo dos bens materiais na família, na medida em que aquilo que os pais dão representa o seu afecto pelos filhos ou vê-se transmutado numa relação de poder entre os irmãos: de quem o pai gosta mais, quem é mais poderoso ou importante na família.

A boa resolução e integração da tarefa são associadas, por doadores e herdeiros, à união e bons valores da família. A herança parece deter um carácter de prova social, no sentido em que coloca os pais perante a avaliação externa da sua qualidade parental. Este aspecto torna-se ainda mais saliente porque às famílias portuguesas são atribuídos valores nucleares como honra, respeito, bondade e confiança (Araújo-Lane, 2005). Isto faz com que para os doadores, os conflitos e a não resolução da herança possam representar a falência da sua função parental. Para os herdeiros, a resolução positiva da transmissão da herança material poderá servir de modelo a seguir pelos próprios filhos. Como refere Wolff (2001) os pais têm usado o seu comportamento em relação aos avós para modelar o comportamento dos filhos em relação a si. 


\section{Implicações}

\section{Dinâmica familiar nas familias envelhecidas}

As implicações da herança nas relações familiares podem sentir-se antes da morte dos pais, na preparação da herança e na gestão diária dos bens e funções familiares. Neste período é possível que se estabeleça uma relação de desconfiança entre irmãos e entre pais e filhos, fazendo com que todos ajam de modo reservado para evitar conflitos. Os filhos mostram alguma resistência em abordar a herança, mas quando os pais tomam as primeiras decisões, podem instalar-se tensões. Numa fratria alargada é provável que sejam os filhos com maior proximidade geográfica e/ou emocional aos pais que auxiliem na gestão dos bens, o que suscitará a desconfiança dos irmãos mais afastados. Os pais poderão utilizar os seus bens para assegurar a prestação de cuidados na velhice, mas isso contribuirá para aumentar a desconfiança e a tensão entre doadores e herdeiros. Para além disso, é possível que o casal idoso entre em desacordo, sobre que bens doar, a quem e quando doar.

Para os pais idosos os bens materiais constituem uma reserva de poder. Os doadores entendem a herança como a transmissão dos bens após a morte, revelando o seu desejo de reservar a posse (total ou parcial) dos seus bens até ao fim. Quando os herdeiros, pressionados por necessidades económicas, queiram receber antecipadamente a sua parte de herança, é expectável que se instalem conflitos, relações de desconfiança e ressentimento.

Com a morte dos pais, as maiores dificuldades familiares parecem concentrar-se no processo de distribuição da herança. Para os herdeiros, os maiores problemas surgem nesta etapa, quando a ausência dos pais permite transformar as suas relações, pela primeira vez, em relações voluntárias, sentindo-se livres para disputar ou fazer emergir rivalidades antigas. Os conflitos poderão associar-se à dificuldade de harmonizar significados e valores afectivos atribuídos aos bens ou acentuar-se perante a existência de discordâncias anteriores, como por exemplo em relação à prestação de cuidados aos pais, ou perante diferenças socio-económicas e culturais entre os irmãos.

Isto significa que quando a gestão da herança é lançada em vida pelos pais a sua resolução formal poder ser preparada/concretizada antes da sua morte, por exemplo, através da distribuição e escrituração de alguns bens em vida. Contudo, a resolução emocional da tarefa sobrevive à morte dos doadores e, nalguns casos, será alcançada na sua ausência. Assim, podemos considerar que a tarefa transmissão da herança material comporta duas dimensões: i) legal, preparação da herança em vida e resolução formal do processo; ii) emocional, prolongada para além da morte dos pais (desafio específico para os herdeiros). A resolução 
emocional da herança é mais longa e nem sempre cronologicamente coincidente com a resolução formal/legal.

\section{Intervenção familiar}

Doadores e herdeiros tendem a valorizar a resolução da herança sem intervenção de terceiros (parentes afins ou profissionais). Talvez por isso sejam os profissionais que relatem mais casos extremos de conflito. Tal como noutras situações em que a família está sujeita a fontes de stress, é pertinente perceber se o problema advém do contexto (exemplo desemprego dos filhos ou dificuldades económicas) ou se representa uma dificuldade recorrente da família (exemplo más relações entre pais e filhos).

Muitos conflitos em torno da herança estão associados aos significados e valores familiares, os quais mantêm uma relação com o contexto social e cultural e com a história de cada família. Assim, conhecer valores e significados que doadores e herdeiros detêm, tais como igualdade e justiça, pode ajudar a compatibilizar as suas perspectivas para chegar a uma resolução mutuamente satisfatória.

Conhecer os mitos e crenças familiares (heranças emocionais), como por exemplo, o mito da unidade familiar (que emergiu expressivamente nos resultados) tornase essencial na medida em que poderão influenciar a forma como as heranças (materiais) são distribuídas. Num contexto de intervenção, o “desvelar" dos mitos ajuda a clarificar as relações entre os envolvidos e contribui para ajudar a família a metacomunicar sobre a herança. Desse modo ficariam mais claros os objectivos, necessidades e as intenções de quem dá e de quem recebe.

A família tende a encarar a herança como um processo burocrático e conflituoso que põe à prova à sua integridade e bons valores. Neste sentido, o recurso à informação e aos modelos psicoeducativos poderá constituir um instrumento útil de intervenção, já que permite baixar a tensão, gerir as emoções, normalizar os sentimentos de culpa e de desadequação e envolver todos num processo de colaboração que os torna mais consciente das suas competências para resolver o problema.

\section{Limites e perspectivas de pesquisa}

Um dos principais limites deste estudo centra-se no número reduzido de participantes, contudo a pesquisa responde somente a objectivos exploratórios. São necessários estudos sobre diferentes estruturas e contextos socio-culturais como as famílias reconstituídas, famílias de quatro gerações, pessoas solteiras ou 
casais sem filhos, famílias com baixos recursos, os quais poderão revelar outros padrões de transmissão, competências e estratégias, assim como apontar para outros valores e significados.

Futuras pesquisas devem a profundar padrões transaccionais, incluindo questões como: "o que sentem as pessoas ao dar/receber?"; "quais os aspectos mais positivos e negativos de dar/receber?"; "quem toma decisões?"; "quem as contesta?"; "o que gostaria que tivesse acontecido como herdeiro/doador?", bem como a profundar o estudo dos valores e significados subjacentes à transmissão/recepção dos bens (em particular da igualdade e justiça), a sua construção ao longo da vida e ligação à história familiar.

\section{Conclusões}

Este estudo tem como finalidade contribuir para a compreensão do papel da herança material na dinâmica das famílias envelhecidas, a partir da perspectiva do ciclo da vida familiar. Os resultados indicam que a herança encontra-se intrinsecamente associada a vicissitudes do desenvolvimento individual e familiar, respondendo a solicitações externas e legais e a necessidades económicas, emocionais e relacionais de doadores e herdeiros.

A gestão da herança como tarefa do ciclo vital familiar faz emergir dois grandes desafios emocionais/relacionais: i) o da continuidade (continuar-se/dar continuidade), que acarreta lidar com uma situação paradoxal em que se ganha com a perda (real ou simbólica), aceitar alterações nos papéis geracionais, definir a relação com o doador e integrar o seu papel na família; e ii) o da sucessão (ser sucedido/suceder) que remete para um jogo de reciprocidade entre doadores e herdeiros prolongado no tempo, para a renegociação do poder executivo e para a gestão da igualdade e da justiça nas relações entre pais e filhos e entre irmãos.

A herança parece constituir um desafio normativo, um ponto nodal onde se actualizam relações e modos de funcionamento familiar, do presente e do passado, e múltiplos percursos de desenvolvimento. Perspectiva-se assim o seu papel nas famílias envelhecidas: 1) como oportunidade de transformação das relações, de acordo com as necessidades do ciclo vital, centradas no dinheiro/bens e suporte; 2) como momento potencial para a reparação relacional ou redefinição de relações pais-filhos, filhos-filhos e no casal; e de revisão e integração da experiência de vida; 3) como ocasião ritual, definida socialmente e pela família, para transmissão de um legado material e simbólico.

Na família actual, a transmissão da herança parece continuar a apontar para a manutenção e preservação do sistema familiar (real ou emocional), embora os 
conteúdos e os processos de transmissão possam ter adquirido diferentes formas ao longo do tempo.

\section{Referências bibliográficas}

Belk, R. (1988). Possessions and the extended self. Journal of Consumer Research, 15: 139-168. Bernheim, B. \& Severinov, S. (2003). Bequests as signal: an explanation for the equal division puzzle. Journal of Political Economy, 111: 733-764.

Bernheim, Shleifer \& Summers (1985). The strategic bequest motive. Journal of Political economy, 93(6): 1045-1076.

Carter, B. \& McGoldrick, M. (Eds.). (1999). The expanded family life cycle. (3 ed). Needham Heights: Allyn \& Bacon, 362-372.

Cole, C. (1986). Developmental tasks affecting the marital relastionship in later life. American Behavioral Scientist, 29(4): 389-403.

Cox, D. \& Rank, M. (1992). Inter-vivos transfers and intergenerational exchange. The Review of Economics and Statistics: 305-314.

Drake, D. \& Lawrence, J. A. (2000). Equality and distributions of inheritance in families. Social Justice Research, 13 (3): 271-290.

Finch, J., Mason, J., Masson, J., Wallis, L., Hayes, L. (1996). Wills, inheritance and families. Oxford: Oxford University Press.

Hogan, D., Eggebeen, D. \& Clogg, C. (1993). The structure of intergenerational exchanges in American families. American Journal Sociology, 98(6): 1428-1458.

Kemp, S. \& Hunt, F. (2001). Exploring the Psychology of inheritances. Zeitschrift für Sozialpsychologie, 32 (3): 171-179.

Kohli, M. \& Künemund, H. (2003). Intergenerational transfers in the family. In. V. Bengston \& A. Lowenstein (Eds.). Global aging and challenges to families. New York: Aldine de Gruyter, 123-142.

Lustbader, W. (1996). Conflict, emotion and power surrounding legacy. Generations, 20(3): 54-59.

McGarry, K. (1999). Inter-vivos transfers and intended bequests. Journal of Public Economics, 73: 321-351.

Price, L. Arnould, E. \& Curasi, C. (2000). Older consumer's disposition of special possessions. Journal of Consumer Research, 27(2): 179-201.

Sousa, L., Figueiredo, D.\& Cerqueira, M. (2004). Envelhecer em familia. Porto: Porto Editora. Sussman, M., Cates, J. \& Smith, D. (1970). The family and inheritance. New York: Russel Sage . Stum, M. (2000). Families and inheritance decisions. Journal of Family and Economic Issues, 21 (2): 177-202.

Telles, G. (1991). Direito das sucessões. Noções fundamentais. Coimbra: Coimbra Editora

Titus, L., Rosenblatt, C. \& Anderson, M. (1979). Family conflict over inheritance of property. The family coordinator, 28(3), 337-346.

Wolff, François-Charles (2001). Private intergenerational contact in France and the demonstration effect. Applied Economics, 33: 143-153. 


\section{Material inheritance: a normative task for families in later life}

The transmission of material inheritance is an expected event in later life families, reflecting on the dynamics and quality of family relationships. However, it is a subject scarcely discussed in the psychological and family literature. This article presents an exploratory study on the transmission of material inheritance, addressing it from the family life cycle perspective. Methodology is based in semi-structured interviews applied to three focus group consisting of donors, heirs and professionals involved with older people, to understand their experiences around material inheritance. Results suggest that the transmission of material inheritance emerges as a normative task of the family life cycle, coupled with the elder's development. Task combines socio-economic conditions, family processes and dynamics and confronts family with significant emotional and relational challenges. Its resolution enhances both individual and family integrity in later life.

KEY-WORDS: Material inheritance; Family life cycle; Later life family; Family life cycle tasks.

Transmettre l'héritage: une tâche normative des familles à la fin de la vie

La transmission de l'héritage matériel est un événement attendu dans la vie des familles envieillies, reflétant sur la dynamique et la qualité des relations familiales. Toutefois, il est un sujet peu discuté dans la littérature psychologique et de la famille. Cet article présente une étude exploratoire sur la transmission de l'héritage matériel, dans la perspective du cycle de la vie familiale. La méthodologie est basée sur des entretiens semi-structurés appliquée à trois groupes de discussion composé de donateurs, bénéficiaires et des professionnels concernés par les personnes âgées, à comprendre leurs expériences avec l’héritage matériel. Les résultats suggèrent que la transmission d'héritage matériel apparaît comme une tâche normative du cycle de la vie familiale. La tâche combine les conditions socio-économiques, des processus et dynamiques familiales, confrontant la famille à des importants défis relationnelles et affectives. Sa résolution contribue à la l'intégrité individuel et familiale dans la fin de la vie.

MOTS-CLÉS: Héritage; Cycle de la vie familiale; Familles envieillies, Tâches du cycle de la vie familiale. 